\title{
Inter-individual variation in DNA damage and base excision repair in young, healthy non-smokers: effects of dietary supplementation and genotype
}

\author{
Fiona Caple ${ }^{1,2,3}$, Elizabeth A. Williams ${ }^{2,4}$, Alison Spiers ${ }^{1,2}$, John Tyson ${ }^{2,5}$, Brian Burtle ${ }^{1}$, Ann K. Daly ${ }^{6}$, \\ John C. Mathers ${ }^{2,5}$ and John E. Hesketh ${ }^{1,2 *}$ \\ ${ }^{1}$ Institute for Cell and Molecular Biosciences, Medical School, Newcastle University, Newcastle upon Tyne NE2 4HH, UK \\ ${ }^{2}$ Human Nutrition Research Centre, Newcastle University, Newcastle upon Tyne NE2 4HH, UK \\ ${ }^{3}$ School of Applied Sciences, Northumbria University, Newcastle upon Tyne NE1 8ST, UK \\ ${ }^{4}$ Human Nutrition Unit, Department of Oncology, University of Sheffield, Sheffield S10 2RX, UK \\ ${ }^{5}$ Institute for Ageing and Health, Medical School, Newcastle University, Newcastle upon Tyne NE2 4HH, UK \\ ${ }^{6}$ School of Clinical Laboratory Sciences, Medical School, Newcastle University, Newcastle upon Tyne NE2 4HH, UK
}

(Received 17 June 2009 - Revised 16 October 2009 - Accepted 20 November 2009 - First published online 19 January 2010)

\begin{abstract}
Diets rich in fruits and vegetables are associated with lower risk of cancer which may be conferred in part by the antioxidant properties of these foods. However, antioxidant supplementation or increased consumption of antioxidant-rich foods has been reported to have inconsistent effects on DNA damage. The present work (the DART study) investigated the extent of inter-individual variation in DNA damage, the capacity for base excision repair (BER) and the responses of both variables to supplementation with an antioxidant supplement for 6 weeks. There was a wide inter-individual variation in endogenous lymphocyte DNA strand breaks (8-fold variation), in damage after a challenge with $\mathrm{H}_{2} \mathrm{O}_{2}(16$-fold variation) and in DNA repair (41-fold variation) measured using the comet assay. When stratified into tertiles according to the pre-supplementation level of endogenous DNA damage, there was a statistically significant decrease in DNA damage after supplementation in the tertile with the highest pre-supplementation level of damage. There was no effect of supplementation on BER. Endogenous DNA damage level before supplementation was significantly different $(P=0.037)$ between the three genotypes for the Val16Ala single nucleotide polymorphism in manganese superoxide dismutase (rs4880) with individuals homozygous/wild type showing less damage than those carrying the alanine variant.
\end{abstract}

Antioxidants: DNA damage: Base excision repair: Genotypes: Superoxide dismutase

Reactive oxygen species, generated as a consequence of cellular metabolism and environmental stress ${ }^{(1)}$, have the potential to modify and damage DNA. Oxidative DNA damage is implicated in carcinogenesis ${ }^{(2)}$ and in ageing and its associated chronic diseases that are characterised by an accumulation of DNA damage ${ }^{(3,4)}$. Endogenous cellular defence mechanisms responsible for preventing damage by reactive oxygen species include catalase, superoxide dismutase and the Se-dependent glutathione peroxidases ${ }^{(1)}$. Antioxidant defence is also provided by the exogenous vitamins A, C and E. Despite these defence mechanisms, five multienzyme DNA repair mechanisms are required in mammalian cells: base excision repair (BER); nucleotide excision repair (NER); direct repair; post-replication repair; mismatch repair ${ }^{(5,6)}$. Of these, BER is the principal mechanism responsible for maintaining the integrity of the human genome against oxidative damage.

Diets rich in fruits and vegetables are associated with reduced risk of cancer ${ }^{(7)}$ and this apparent protection may be conferred in part by the antioxidant properties of these foods. The underlying mechanisms may include nutritional modulation of the cellular processes which protect DNA from damage or which repair DNA. Several in vivo studies have investigated the potential benefits of fruit and vegetables, fruit and vegetable juices and extracts or supplementation with selected antioxidants on DNA damage and repair ${ }^{(8-21)}$. Overall, there is considerable heterogeneity in the reported effects of antioxidant supplementation or increased consumption of antioxidant-rich foods on endogenous DNA damage and/or damage induced by an $\mathrm{H}_{2} \mathrm{O}_{2}$ challenge ${ }^{(22)}$, and only a limited number of studies have demonstrated benefit in terms of DNA repair ${ }^{(23-26)}$.

The lack of consistency in outcomes from these studies may be attributable to differences in study designs including the nature and duration of intervention and the age, sex, health status and lifestyle characteristics of the study populations. There are few data on inter-individual variation in capacity for $\mathrm{BER}^{(27)}$ although, in a companion study, we have reported elevenfold between-person variation in capacity for NER in healthy, young volunteers and substantial within-person variation $^{(26)}$. While it is clear that single nucleotide

\footnotetext{
Abbreviations: BER, base excision repair; FRAP, ferric reducing antioxidant power; NER, nucleotide excision repair; SNP, single nucleotide polymorphisms; TEAC, Trolox total equivalent antioxidant capacity.

* Corresponding author: Professor John E. Hesketh, fax +44 191222 7424, email j.e.hesketh@ncl.ac.uk
} 
polymorphisms (SNP) in key defence and repair genes may influence an individual's susceptibility to DNA damage and ability to repair $\mathrm{DNA}^{(28-30)}$, there has been little research on the relevance of these SNP to DNA damage in healthy individuals $^{(31)}$. The aims of the present study (the DNA damage and repair trial; the DART study) were to investigate the extent of inter-individual variation in DNA damage, as measured by DNA strand breaks, and capacity for BER and inter-individual variation in the response of BER and damage to DNA to a 6-week supplementation with dietary antioxidants. In addition, a pilot study was carried out to explore the relationship between these parameters and genotype for polymorphisms in key antioxidant defence genes.

\section{Materials and methods}

\section{Participants}

Participants were recruited by advertisement at Newcastle University, Newcastle upon Tyne, UK and were between 18 and 30 years old. Exclusion criteria were smoking and current use of nutritional supplements. A total of fifty-four volunteers were recruited and forty-eight subjects (seventeen male, thirtyone female, mean age 21 years, Table 2) completed the study. Five withdrew from the study giving no reason and blood could not be collected from another. The present study was conducted according to the guidelines laid down in the Declaration of Helsinki and all procedures involving human subjects/patients were approved by the Newcastle and North Tyneside Health Authority Joint Ethics Committee. Written informed consent was obtained from all the subjects.

\section{Dietary assessment}

Habitual dietary intake was estimated at recruitment using a self-administered FFQ that was a modified version of the previously validated European Prospective Investigation of Cancer $\mathrm{FFQ}^{(32)}$. These minor modifications reflected the typical diet of the North-East of England population. The data were entered into SPSS and analysed using an in-house database using an approach similar to that described by Welch et al. ${ }^{(33)}$.

\section{Supplement}

The antioxidant supplement was a commercially available over the counter product suitable for vegetarians. The supplement provided $100 \mu \mathrm{g}$ Se, $450 \mu \mathrm{g}$ vitamin A (300 $\mu \mathrm{g}$ retinol equivalent retinol, $150 \mu \mathrm{g}$ retinol equivalent $\beta$-carotene), $90 \mathrm{mg}$ vitamin $\mathrm{C}$ and $30 \mathrm{mg}$ vitamin $\mathrm{E}$ per capsule (Wassen International Ltd, Surrey, UK).

\section{Study protocol}

The subjects were asked to refrain from strenuous physical activity and to abstain from alcohol for $2 \mathrm{~d}$ before blood collection. Of the forty-eight volunteers recruited, eight were randomly allocated to a so-called 'wild'(23) or control group who took no supplement. The remaining subjects were provided with the supplements and instructed to take one capsule daily for 6 weeks while following their normal diet; forty-eight individuals completed the 6-week supplementation period. At baseline and after 6 weeks of supplementation, fasting blood samples $(40 \mathrm{ml})$ were collected in evacuated containers containing EDTA. Lymphocytes were isolated immediately from $20 \mathrm{ml}$ blood and an aliquot was cryopreserved for subsequent single-cell gel electrophoresis analysis for assay of DNA strand breaks. A second aliquot of lymphocytes was used immediately to prepare an extract for assay of BER. Whole blood was frozen at $-80^{\circ} \mathrm{C}$ for DNA extraction. Plasma was frozen at $-80^{\circ} \mathrm{C}$ for subsequent antioxidant analysis. Body weight and height were self-reported.

\section{Single-cell gel electrophoresis analysis (comet assay)}

Lymphocytes were separated immediately after blood sample collection using density gradient sedimentation (Histopaque 1077; Sigma-Aldrich, Inc., St Louis, MO, USA) and frozen at a density of $3 \times 10^{6}$ per $\mathrm{ml}$ in $90 \%$ heat-treated fetal calf serum $/ 10 \%$ dimethyl sulphoxide (DMSO). Endogenous strand breaks and induced DNA damage were measured in lymphocytes collected from a given subject on the same day. Cells were recovered by washing in cold PBS and resuspended in Roswell Park Memorial Institute (RP $\mu \mathrm{I})$ medium containing $10 \%$ fetal calf serum. To assess resistance to induced oxidative DNA damage, lymphocytes were exposed to $150 \mu \mathrm{M}-\mathrm{H}_{2} \mathrm{O}_{2}$ for $5 \mathrm{~min}$ before embedding in $85 \mu \mathrm{l}$ of $1 \%$

Table 1. Primers, PCR conditions and restriction digestion parameters used in genotyping*

\begin{tabular}{|c|c|c|c|}
\hline & GPX4 & $G P X 1$ & $M n S O D$ \\
\hline Forward primer & GACCTGCCCCACTATTTCTA & GCCCTGACGGTGTGCCCCTA & CAGCCCAGCCTGCGTAGACGG \\
\hline Reverse primer & GTCTGTTTATTCCCACAAGG & TGCTGACACCCGGCACTTTATTAG & CTTGGCCAACGCCTCCTGGTACTT \\
\hline Cycles & 34 & 30 & 34 \\
\hline Denaturing & $95^{\circ} \mathrm{C}, 15 \mathrm{~s}$ & $94^{\circ} \mathrm{C}, 45 \mathrm{~s}$ & $94^{\circ} \mathrm{C}, 60 \mathrm{~s}$ \\
\hline Annealing & $53.5^{\circ} \mathrm{C}, 30 \mathrm{~s}$ & $58^{\circ} \mathrm{C}, 45 \mathrm{~s}$ & $63^{\circ} \mathrm{C}, 60 \mathrm{~s}$ \\
\hline Extension & $72^{\circ} \mathrm{C}, 1 \mathrm{~min}$ & $72^{\circ} \mathrm{C}, 45 \mathrm{~s}$ & $72^{\circ} \mathrm{C}, 60 \mathrm{~s}$ \\
\hline \multirow[t]{2}{*}{ Polymorphism } & T718C & Pro198Leu & Val16Ala \\
\hline & rs 713041 & rs1050450 & rs4880 \\
\hline Enzyme & Styl & Apal & BsaW1 \\
\hline \multirow[t]{3}{*}{ Products } & $\mathrm{C} / \mathrm{C}=159,62 \mathrm{bp}$ & Pro/Pro $=88,223 b p$ & $\mathrm{Ala} / \mathrm{Ala}=174 \mathrm{bp}$ \\
\hline & $\mathrm{T} / \mathrm{T}=97,62,62 \mathrm{bp}$ & Leu/Leu $=311 \mathrm{bp}$ & $\mathrm{Ala} / \mathrm{Val}=174,83 \mathrm{bp}$ \\
\hline & $\mathrm{C} / \mathrm{T}=159,97,62,62 \mathrm{bp}$ & Pro/Leu $=88,223,311 b p$ & $\mathrm{Val} / \mathrm{Val}=83 \mathrm{bp}$ \\
\hline
\end{tabular}

GPX, glutathione peroxidase; $M n S O D$, manganese superoxide dismutase.

${ }^{*}$ Restriction digestion was used to genotype individuals for variants in the genes encoding GPX 1 and 4 and MnSOD. Primer sequences and conditions for PCR amplification are shown as well as the details of restriction enzymes and digestion products. 
Table 2. Baseline characteristics of study participants*

(Mean values with their standard errors)

\begin{tabular}{|c|c|c|c|c|c|c|c|c|c|}
\hline & \multicolumn{3}{|c|}{ All } & \multicolumn{2}{|c|}{ Supplement group } & \multicolumn{3}{|c|}{ Control group } & \multirow[b]{2}{*}{$P \dagger$} \\
\hline & Mean & $n 48$ & SEM & Mean & $n 40$ & Mean & $n 8$ & SEM & \\
\hline Age (years) & 21 & & $2 \cdot 9$ & 21 & $3 \cdot 1$ & 21 & & 1.5 & 0.483 \\
\hline \multicolumn{10}{|l|}{ Sex } \\
\hline Male, $n(\%)$ & $17(35)$ & & & $13(33)$ & & $4(50)$ & & & 0.345 \\
\hline \multirow{2}{*}{ Female, $n(\%)$} & $31(65)$ & & & $27(67)$ & & $4(50)$ & & & \\
\hline & \multicolumn{3}{|c|}{$n 44$} & \multicolumn{2}{|r|}{$n 36$} & \multicolumn{3}{|c|}{$n 8$} & \\
\hline Weight (kg) & 67 & & $2 \cdot 1$ & 66 & $2 \cdot 4$ & 71 & & 3.5 & 0.330 \\
\hline Height $(\mathrm{m})$ & 1.70 & & 0.016 & 1.69 & 0.019 & 1.73 & & 0.022 & 0.326 \\
\hline \multirow[t]{2}{*}{ BMI $\left(\mathrm{kg} / \mathrm{m}^{2}\right)$} & $23 \cdot 0$ & & 0.549 & 22.9 & 0.646 & 23.6 & & 0.860 & 0.623 \\
\hline & \multicolumn{3}{|c|}{$n 46$} & \multicolumn{2}{|c|}{$n 38$} & \multicolumn{3}{|c|}{$n 8$} & \\
\hline Energy intake (kJ) & 12540 & & $614 \cdot 1$ & 12793 & $706 \cdot 3$ & 11168 & & $1048 \cdot 7$ & 0.320 \\
\hline Protein intake $(\mathrm{g} / \mathrm{d})$ & 112 & & 5.9 & 113 & 6.9 & 107 & & $10 \cdot 3$ & 0.701 \\
\hline Carbohydrate intake (g/d) & 380 & & 191 & 390 & $22 \cdot 1$ & 336 & & $28 \cdot 3$ & 0.282 \\
\hline Fat intake $(\mathrm{g} / \mathrm{d})$ & 102 & & $5 \cdot 7$ & 105 & $6 \cdot 6$ & 86 & & 7.9 & 0.197 \\
\hline Fat (as \% of total energy intake) & 29.9 & & 0.69 & $30 \cdot 1$ & 0.81 & 28.5 & & 0.95 & 0.407 \\
\hline Alcohol (as \% of total energy intake) & 3.9 & & 0.62 & $3 \cdot 7$ & 0.65 & $5 \cdot 0$ & & 1.81 & 0.421 \\
\hline Fruit and vegetables (portions/week) & 17 & & 1.6 & 17 & 1.6 & 17 & & $5 \cdot 3$ & 0.931 \\
\hline
\end{tabular}

* Sex, age, height and weight of volunteers were recorded at baseline. Macronutrient intake and fruit and vegetable consumption was estimated using FFQ.

$\dagger$ No statistically significant differences were observed between the supplement and control group at baseline (ANOVA for continuous variables, $\chi^{2}$ test for categorical variable).

low-melting point agarose. For measurement of both endogenous and induced damages, cells suspended in agarose were then transferred to a microscope slide previously coated with $1 \%$ normal-melting point agarose and covered quickly with a glass coverslip. Once the gel had set, the coverslip was removed and the cells were lysed in $2.5 \mathrm{M}-\mathrm{NaCl}$, 0.1 M-EDTA, $10 \mathrm{~mm}$-2-amino-2-hydroxymethyl-propane-1,3diol (Tris), $\mathrm{pH} 10,10 \%$ DMSO, $1 \%$ Triton-X100 at $4{ }^{\circ} \mathrm{C}$ for $1 \mathrm{~h}$, then treated with alkali $(0 \cdot 3 \mathrm{M}-\mathrm{NaOH}, 1 \mathrm{~mm}-\mathrm{EDTA})$ for $40 \mathrm{~min}$ before electrophoresis at $4^{\circ} \mathrm{C}$ for $30 \mathrm{~min}$ at $25 \mathrm{~V}$ $300 \mathrm{~mA}$. The slides were washed three times in $0.4 \mathrm{M}$-Tris$\mathrm{HCl}, \mathrm{pH} 7.5$ to neutralise and were stained with $4^{\prime}, 6$-diamidino-2-phenylindole to allow visualisation by fluorescent microscopy using an Olympus BX51 microscope. Digital images were captured using an Olympus DP50 digital camera and Analysis Viewfinder Lite SIS Software. DNA strand breaks were measured using Komet 5.5 software (Kinetic Imaging, Liverpool, UK) and expressed as mean percentage of fluorescence in the DNA tail of 100 cells. All the samples were assayed in duplicate and results were normalised to a quality control sample that was analysed with each batch of samples.

\section{DNA repair assay}

BER was measured using a modified comet assay ${ }^{(23)}$. Lymphocytes were washed in $13.5 \mathrm{~mm}-\mathrm{HEPES}, 0.12 \mathrm{M}-\mathrm{KCl}$, 0.3 mM-EDTA, 0.03 mM-dithiothreitol, $3 \%$ glycerol, $\mathrm{pH} 7 \cdot 8$. Cells were resuspended and frozen in $45 \mathrm{mM}$-HEPES, $0 \cdot 4 \mathrm{M}-\mathrm{KCl}, 1 \mathrm{~mm}$-EDTA, $0 \cdot 1 \mathrm{~mm}$-dithiothreitol, $10 \%$ glycerol as $50 \mu \mathrm{l}$ aliquots at a concentration of $10^{8}$ cells per $\mathrm{ml}$. This extract was then used to repair 8-oxoguanine sites induced in lysed HeLa cells by the action of visible light on the photosensitiser Ro 19-8022 (a gift from F Hoffman la Roche, Basel, Switzerland). HeLa cells were seeded at a density of
$2 \times 10^{5}$ cells per $35 \mathrm{~mm}$ Petri dish and $48 \mathrm{~h}$ later the cells were treated with $2 \mu \mathrm{M}-\mathrm{Ro} 19-8022$, on ice, and exposed to light $(500 \mathrm{~W}, 5 \mathrm{~min}$, distance $15 \mathrm{~cm})$. HeLa cells were then washed, embedded in low-melting-point agarose and incubated in lysis buffer as in the comet assay ${ }^{(23)}$. Frozen lymphocyte extract was thawed, centrifuged, resuspended in $40 \mathrm{~mm}$ HEPES, $0 \cdot 1 \mathrm{M}-\mathrm{KCl}, 0.5 \mathrm{mM}$-EDTA, $0.1 \mathrm{mg} / \mathrm{ml}$ bovine serum albumin, $\mathrm{pH} 7.8$ and incubated with the HeLa cells in a humidified environment at $37^{\circ} \mathrm{C}$ for $20 \mathrm{~min}$ before being placed on ice to stop the reaction. In parallel, control assays were carried out in which either the incubation time was zero, only buffer was added (negative control) or purified formamidopyramidine glycosylase (New England Biolabs, Hitchin, UK) was added as a positive control. The remaining steps (i.e. alkali treatment, electrophoresis and visualisation of DNA strand breaks) were as described earlier. All the samples were assayed in duplicate.

\section{Assay of plasma antioxidant activity}

For analysis of ferric reducing antioxidant power (FRAP), the whole blood samples were centrifuged for $15 \mathrm{~min}$ at $4^{\circ} \mathrm{C}$, and the plasma was snap frozen and stored at $-80^{\circ} \mathrm{C}$ until analysis. The FRAP assay was performed on the plasma samples as described by Nagah \& $\mathrm{Seal}^{(34)}$ based on the method by Benzie \& Strain ${ }^{(35)}$. Values were expressed as ferrous ion equivalent unit of activity. Plasma antioxidant capacity was also measured using the Trolox total equivalent antioxidant capacity (TEAC) assay ${ }^{(34)}$. Results are expressed as Trolox equivalent unit of activity.

\section{Genotyping}

DNA was extracted from $5 \mathrm{ml}$ whole blood using previously described methods ${ }^{(36)}$. DNA (100 ng) was amplified by PCR 
using primers detailed in Table 1 and genotypes were determined by restriction digestion, followed by electrophoresis on either $2 \%$ agarose gels or $10 \%$ polyacrylamide gels in Tris-borate-EDTA buffer.

\section{Statistical analysis}

Data were analysed using SPSS version 12.0.2. Analysis using a Kolmogorov-Smirnov test showed that the data were normally distributed $(P>0 \cdot 05)$. ANOVA was used to compare the supplement and control groups at baseline and post-intervention for all variables measured. DNA damage and repair values were normalised to quality controls. Pre- and post-intervention comet and BER assay data were divided into tertiles and stratified according to pre-supplemented endogenous damage and pre-supplemented BER, respectively, as measured by the comet assay. Differences in DNA strand breaks and BER before and after supplementation for each tertile were analysed by Student's $t$ test. DNA damage and repair in relation to genotype were compared using ANOVA and OR calculated. Statistical significance difference was defined as $P<0 \cdot 05$.

\section{Results}

The DART study was carried out on a group of volunteers who gave blood samples on two occasions for measurement of lymphocyte DNA damage and repair as well as plasma antioxidant status assessed by TEAC and FRAP assays. Forty volunteers were given a commercial vitamin and mineral supplement for the 6 weeks between blood sampling. The primary aim was to study the inter-individual variation in DNA damage and BER repair capacity at baseline and following micronutrient supplementation. Therefore, a 'before intervention' $v$. 'after intervention' study design was adopted. However, since relatively little information is available about the intra-individual variation of these parameters over time, an additional small set of unsupplemented individuals was included in the study. These eight individuals were assigned at random to the wild group who received no supplement. As indicated in Table 2, the volunteers were young adults (18-30 years) of both sexes (seventeen male, thirty-one female). There was no significant difference in any of the dietary and lifestyle characteristics of the subjects between the control and supplemented groups (Table 2). Except for two volunteers in each of the wild and supplemented groups, all the volunteers were of Caucasian origin.

There was no significant difference between the groups in DNA damage, BER repair or antioxidant activity at baseline. There was no association between age and BMI $\left(R^{2} 0.002\right.$, $P=0 \cdot 80$ ), and there was no significant difference between males and females for baseline endogenous damage $(P=0.84), \quad \mathrm{H}_{2} \mathrm{O}_{2}$-induced damage $(P=0.72)$ or for BER $(P=0 \cdot 85)$. Endogenous damage at baseline appeared to increase with increasing age $\left(R^{2} 0 \cdot 15, P=0 \cdot 08\right.$; Fig. 1(a)) and BMI $\left(R^{2} 0 \cdot 15, P=0 \cdot 010\right.$; Fig. $\left.1(\mathrm{~b})\right)$. There were no associations between $\mathrm{H}_{2} \mathrm{O}_{2}$-induced damage and age $\left(R^{2} 0 \cdot 05\right.$, $P=0.14)$ or BMI $\left(R^{2} 0.006, P=0.63\right)$ or between BER and age $\left(R^{2} 0.005, P=0.676\right)$ or BMI $\left(R^{2} 0.001, P=0.87\right)$. There was no association between baseline BER and endogenous DNA damage $\left(R^{2} 0.007, P=0.62\right)$ or $\mathrm{H}_{2} \mathrm{O}_{2}$-induced damage $\left(R^{2} 0 \cdot 16, P=0 \cdot 44\right)$. However, there was an inverse correlation between endogenous DNA damage and NER in lymphocytes (measured using a plasmid-based host cell reactivation assay) from the same volunteers, as reported elsewhere $\left(R^{2} 0 \cdot 17, P=0 \cdot 005\right)^{(26)}$.

Mean endogenous damage before supplementation was $23 \%$ DNA in the tail (comparable to values reported by others using this analysis method ${ }^{(8,11)}$ ), and the net increase after challenge with $\mathrm{H}_{2} \mathrm{O}_{2}$ was approximately $16 \%$. There was wide inter-individual variation in both endogenous DNA damage and the increase in damage after the oxidative challenge in the group before supplementation (endogenous DNA damage and damage after challenge were $7-56 \%$ and
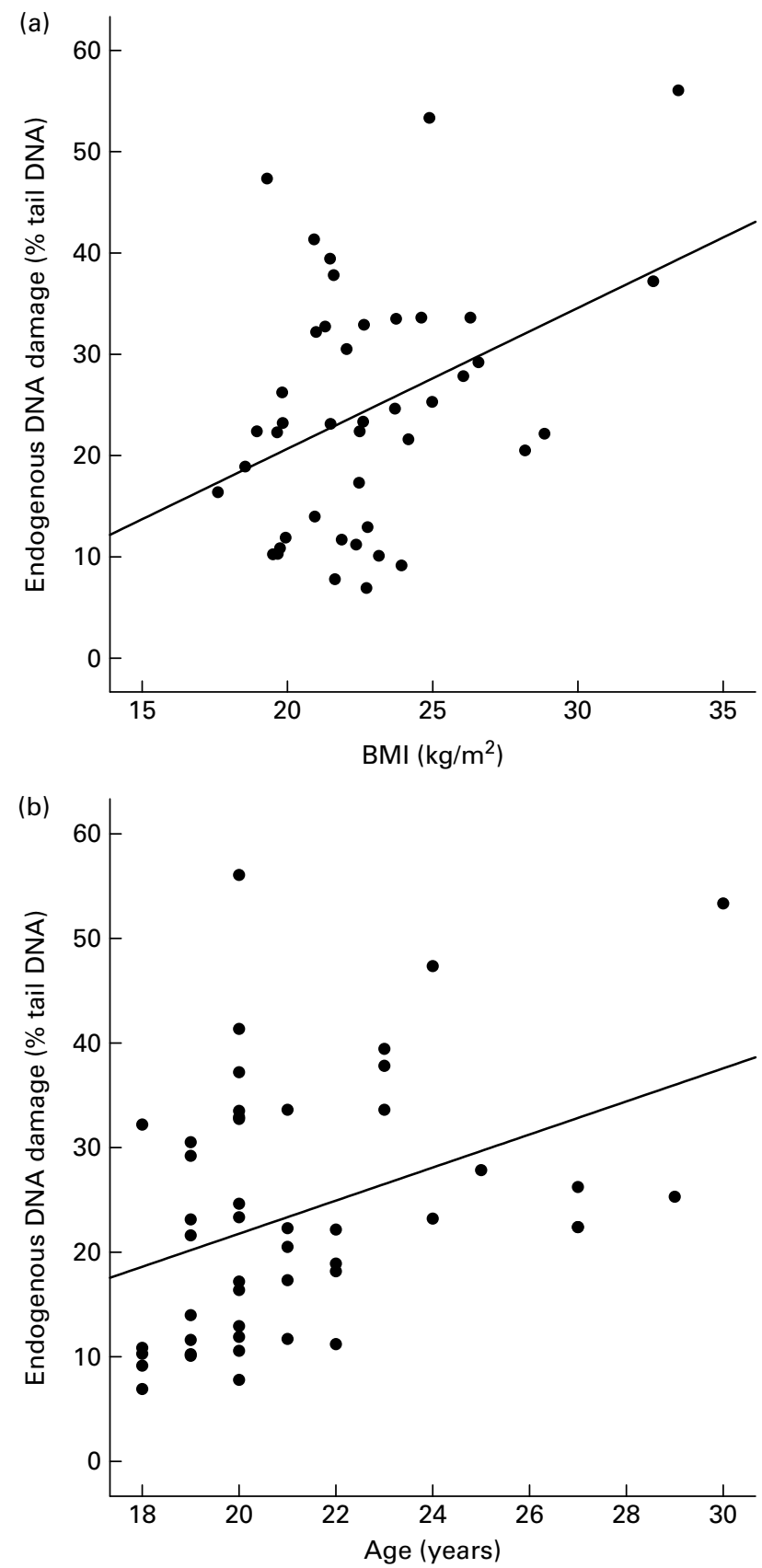

Fig. 1. Relationship between endogenous DNA damage at baseline and BMI and age. Endogenous DNA damage before supplementation was correlated with increased BMI (a) and with increased age (b). 
2-32\% DNA in the tail, respectively). Such variation could reflect the influence of intra-individual variation over time or inter-individual differences in exposure to damaging agents, in antioxidant status and in genetically determined DNA defence mechanisms. Since the data were normalised to a quality control sample, day to day variation in the assay would not be expected to contribute significantly to this inter-individual variation.

As shown in Table 3, supplementation led to a small decrease in mean endogenous damage, but this effect was not statistically significant. However, ranking of the data suggested that the response to supplementation was greatest in individuals who had the highest endogenous damage at baseline (Fig. 2(a)). When the data were stratified into tertiles according to the pre-supplementation level of endogenous damage, there was a significant decrease $(P<0.01)$ after supplementation in the tertile with the highest pre-supplementation level of endogenous damage but not in the other two groups (Table 4). The mean habitual diet (intakes of energy, macronutrients, fruit and vegetables) of the volunteers in this tertile was not significantly different from that of the remaining volunteers and indeed no dietary factors were significantly associated with baseline DNA damage (data not shown). Analysis of covariance with the baseline value as a covariate confirmed that there was a significant difference in response of DNA strand breaks to supplementation across the tertiles $(P=0 \cdot 014)$; no significant differences were seen between tertiles for $\mathrm{H}_{2} \mathrm{O}_{2}$-induced DNA damage $(P=0.817)$ or BER $(P=0.626)$. Supplementation had no significant effect on the level of induced DNA damage following an oxidative challenge with $\mathrm{H}_{2} \mathrm{O}_{2}$ even when the data were stratified according to pre-supplementation levels of induced damage (Table 4; Fig. 2(b)). Thus, overall the data suggest that there is considerable inter-individual variation in both endogenous and $\mathrm{H}_{2} \mathrm{O}_{2}$-induced DNA damage and that in individuals who have a high baseline level of endogenous damage, supplementation with a cocktail of antioxidant vitamins and minerals lowers endogenous lymphocyte DNA damage.

There was an apparent increase in mean TEAC activity after 6 weeks supplementation $(P=0.055)$, but there was no increase over the same time period in the wild group (Table 3). In contrast, there was no increase in FRAP activity following supplementation. The change in TEAC but not FRAP may reflect differences in the components of antioxidant capacity estimated by the two assays; the TEAC assay measures the capacity of the plasma to inhibit the generation of free radicals, whereas the FRAP assay is insensitive to sulphydryl group-containing antioxidants such as glutathione ${ }^{(37)}$. There were no relationships at baseline between antioxidant capacity and endogenous DNA damage, $\mathrm{H}_{2} \mathrm{O}_{2}$-induced damage or DNA repair.

In addition to levels of DNA damage, BER capacity was measured using a modified comet assay. There was a wide variation in BER capacity (0.6-25.0 \% tail DNA) comparable with that found for DNA damage. In addition, the extent of the response of DNA repair to supplementation showed considerable inter-individual variation with approximately $35 \%$ of individuals showing no increase or a lower repair rate after supplementation. The remaining $65 \%$ of the cohort showed a 30 -fold variation in the increase in DNA repair rate (Fig. 2(c)). For the cohort as a whole, or after stratification on the basis of pre-supplementation BER, there was no statistically significant evidence that vitamin and mineral supplementation affected BER (Table 4). Pre- and postsupplementation measurements were significantly correlated for $\operatorname{BER}\left(R^{2} 0.52, P<0.001 ;\right.$ Fig. 3) and $\mathrm{H}_{2} \mathrm{O}_{2}$-induced damage $\left(R^{2} 0 \cdot 101, P<0 \cdot 034\right)$.

Table 3. Endogenous DNA damage, hydrogen peroxide-induced DNA damage and base excision repair in lymphocytes and antioxidant activity in plasma from healthy, young non-smokers before and after 6 weeks antioxidant supplement ${ }^{\star}$

(Mean values with their standard errors)

\begin{tabular}{|c|c|c|c|c|c|c|c|}
\hline & \multirow[b]{2}{*}{$n$} & \multicolumn{2}{|c|}{ Week $0 \dagger$} & \multicolumn{2}{|c|}{ Week 6} & \multirow[b]{2}{*}{$P \neq$} & \multirow[b]{2}{*}{$P \S$} \\
\hline & & Mean & SEM & Mean & SEM & & \\
\hline \multicolumn{8}{|c|}{ Endogenous DNA damage (\%tail DNA) } \\
\hline Supplement & 39 & $24 \cdot 6$ & $2 \cdot 02$ & $20 \cdot 9$ & 1.61 & 0.112 & \multirow[t]{2}{*}{0.367} \\
\hline Control & 7 & $18 \cdot 6$ & 3.04 & $16 \cdot 1$ & $2 \cdot 21$ & 0.175 & \\
\hline \multicolumn{8}{|c|}{ Hydrogen peroxide-induced DNA damage (\%tail DNA) } \\
\hline Supplement & 38 & $17 \cdot 1$ & 1.23 & $16 \cdot 6$ & 1.49 & 0.740 & \multirow[t]{2}{*}{0.420} \\
\hline Control & 7 & $16 \cdot 1$ & $2 \cdot 68$ & $19 \cdot 0$ & 2.01 & 0.256 & \\
\hline \multicolumn{8}{|c|}{ Base excision DNA repair (incision activity) } \\
\hline Supplement & 32 & $7 \cdot 7$ & 0.84 & 7.9 & 0.87 & 0.616 & \multirow[t]{2}{*}{0.007} \\
\hline Control & 8 & $9 \cdot 6$ & 2.42 & $13 \cdot 6$ & $2 \cdot 36$ & 0.114 & \\
\hline \multicolumn{8}{|c|}{ FRAP (ferrous ion equivalents) } \\
\hline Supplement & 40 & 825 & $23 \cdot 8$ & 820 & $22 \cdot 1$ & 0.722 & \multirow[t]{2}{*}{0.641} \\
\hline Control & 8 & 919 & $59 \cdot 0$ & 911 & $66 \cdot 4$ & 0.861 & \\
\hline \multicolumn{8}{|c|}{ TEAC (Trolox equivalents) } \\
\hline Supplement & 40 & 0.719 & 0.008 & 0.730 & 0.008 & 0.055 & \multirow[t]{2}{*}{0.706} \\
\hline Control & 8 & 0.738 & 0.023 & 0.74 & 0.021 & 0.942 & \\
\hline
\end{tabular}

FRAP, ferric reducing antioxidant power; TEAC, trolox total equivalent antioxidant capacity.

* DNA damage (both in isolated lymphocytes and in lymphocytes stimulated with hydrogen peroxide ex vivo) and repair were measured using the comet assay. Damage is presented as mean percentage tail DNA and repair as mean incision activity in arbitrary units. Antioxidant activity in plasma was estimated using FRAP and TEAC assays before and after supplementation.

†ANOVA was used to compare supplement and control groups at baseline. There were no significant differences between the supplement and control group at baseline for any of the variables measured. $P$ values not shown in the table.

$\ddagger$ Variables were compared before and after supplementation using a paired Student's $t$ test.

$\S$ Analysis of covariance was used to compare supplement and control groups post-supplementation with the pre-supplement values as the covariate. 


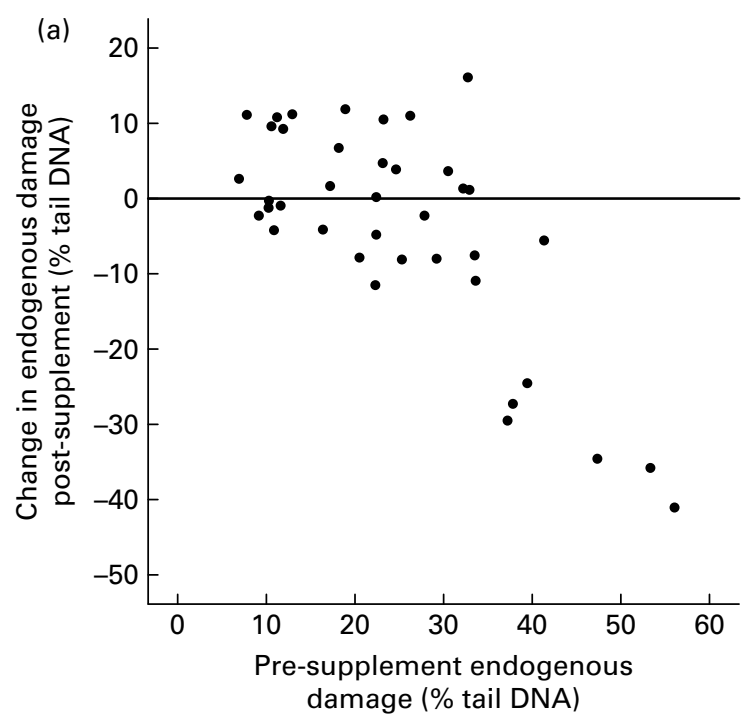

(b)
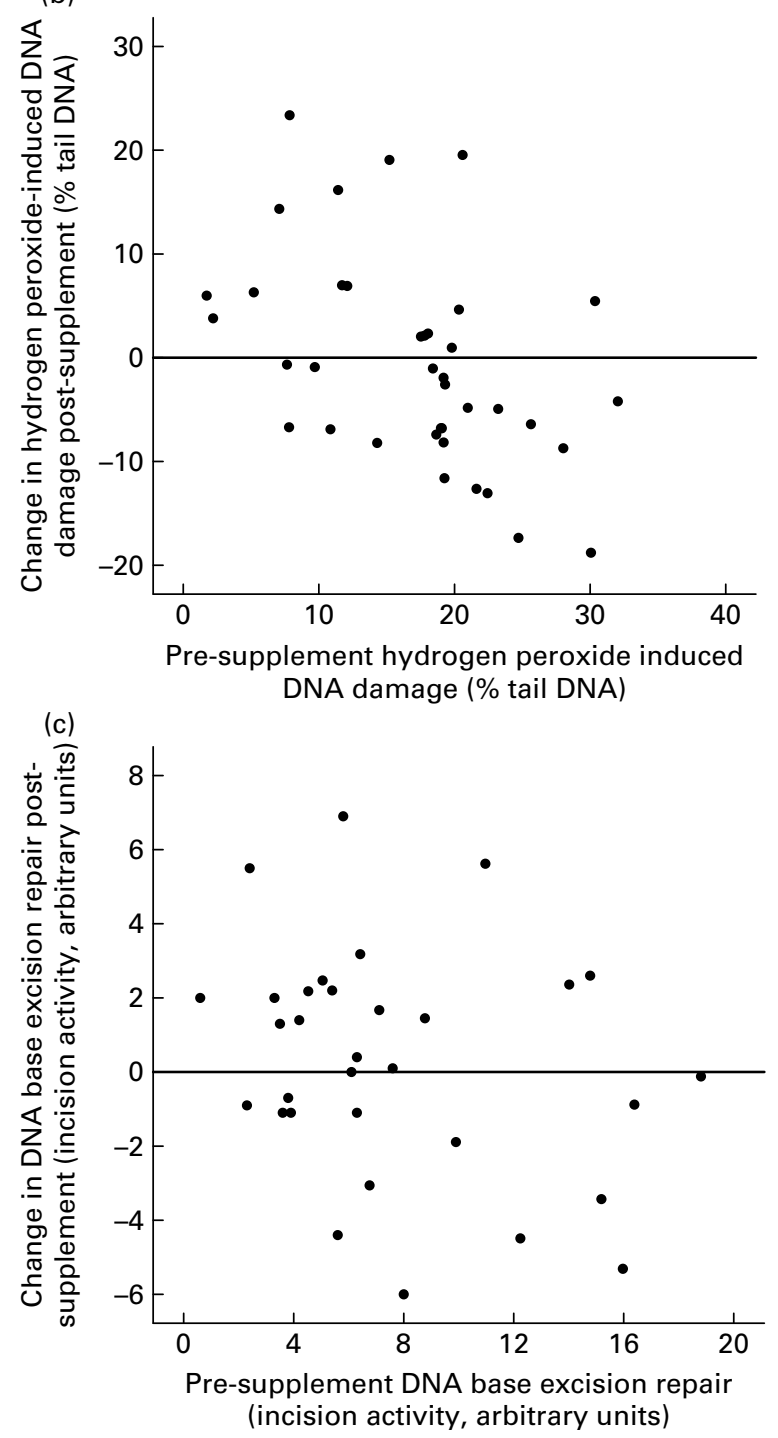

Volunteers were genotyped for three common functionally significant variants in genes encoding important antioxidant protection enzymes (GPX1, GPX4 and MnSOD). Differences in DNA damage on the basis of genotype were compared by ANOVA, and the results are summarised in Table 5. The endogenous DNA damage level before supplementation was significantly different between the three MnSOD genotypes, with individuals homozygous for the valine allele having the lowest level of damage $(P=0.037)$, but the response to supplementation did not differ significantly between the three genotype groups. When tertiles for endogenous DNA damage were related to genotype and the low and medium tertile damage groups were pooled, there was a significant difference between $M n S O D$ frequencies in these groups compared with the high damage group $(\mathrm{OR}=10(95 \% \mathrm{CI}$, $1 \cdot 1,100 \cdot 0) ; P=0.028$ ) for higher damage level in individuals possessing one or two Ala alleles, data not shown). There were no significant differences between levels of endogenous or peroxide-induced damage in respect of GPxl or GPx4 genotype either before or after supplementation.

\section{Discussion}

The cellular mechanisms for defence against DNA damage and those responsible for DNA repair are both critical in maintaining cell integrity. The present results show that levels of endogenous lymphocyte DNA damage and BER and damage induced by exposure of lymphocytes to an in vitro oxidative challenge vary widely even among healthy non-smoking individuals in the age range of 18-30 years. The present study extends earlier suggestions of substantial inter-individual variation in $\mathrm{BER}^{(16,23,27)}$ to a larger population group and complements our findings of large interindividual variation in NER measured by the plasmid-based host cell reactivation assay in the same healthy, young volunteers ${ }^{(26)}$. Further, the present study provides evidence that antioxidant supplementation for 6 weeks led to lower endogenous DNA damage in those individuals with the highest level of damage before supplementation.

The basis for the considerable variation in both DNA damage and BER is not known. Apart from a contribution from within-individual variation, it is possible that the age, sex, health status and lifestyle characteristics of individuals within the study population all contribute to DNA damage and to repair capacity. In addition, inherent, genetically encoded differences in individuals' abilities to protect their DNA from oxidative damage and to repair such damage may influence baseline DNA damage and repair as well as responses to supplementation. For example, 2 to 3 -fold variation in 8-oxoguanine glycosylase activity ${ }^{(37,38)}$ has been observed between individuals and this could contribute to the observed variation in BER. There has been no systematic

Fig. 2. Relationships between the change in endogenous DNA damage, hydrogen peroxide-induced damage and DNA repair after antioxidant supplementation and the baseline parameters. (a) An inverse correlation was observed between the fall in endogenous damage after supplementation and the baseline level of damage (i.e. the biggest decrease in damage was observed in individuals with high levels at baseline). No correlation was observed between the change in either hydrogen peroxide-induced damage (b) or DNA repair (c) and the corresponding baseline levels. 
Table 4. Endogenous DNA damage, hydrogen peroxide-induced damage and base excision repair (BER) in lymphocytes from supplemented individuals before and after 6 weeks antioxidant supplement according to baseline tertiles of endogenous damage and DNA repair*

(Mean values with their standard errors)

\begin{tabular}{|c|c|c|c|c|c|c|c|}
\hline & \multirow[b]{2}{*}{$n$} & \multicolumn{2}{|c|}{ Week 0} & \multicolumn{2}{|c|}{ Week 6} & \multirow[b]{2}{*}{$P \dagger$} & \multirow[b]{2}{*}{$P \neq$} \\
\hline & & Mean & SEM & Mean & SEM & & \\
\hline \multicolumn{8}{|c|}{ Endogenous DNA damage } \\
\hline Low damage tertile & 12 & $10 \cdot 82$ & 0.70 & $14 \cdot 29$ & 1.86 & 0.087 & \\
\hline Mid damage tertile & 12 & $22 \cdot 03$ & 0.82 & 23.56 & $2 \cdot 41$ & 0.524 & \\
\hline High damage tertile & 15 & $37 \cdot 67$ & $2 \cdot 21$ & 24.02 & $2 \cdot 96$ & 0.008 & 0.014 \\
\hline \multicolumn{8}{|c|}{ Hydrogen peroxide-induced DNA damage } \\
\hline Low damage tertile & 12 & $18 \cdot 61$ & 1.77 & $16 \cdot 43$ & $2 \cdot 30$ & 0.508 & \\
\hline Mid damage tertile & 12 & $15 \cdot 69$ & $2 \cdot 86$ & $17 \cdot 41$ & 3.23 & 0.571 & \\
\hline High damage tertile & 14 & 17.03 & 1.80 & $15 \cdot 96$ & $2 \cdot 41$ & 0.671 & 0.817 \\
\hline \multicolumn{8}{|l|}{ DNA repair (BER) } \\
\hline Low repair tertile & 10 & $3 \cdot 21$ & 0.37 & $4 \cdot 27$ & 0.67 & 0.143 & \\
\hline Mid repair tertile & 12 & $6 \cdot 37$ & 0.25 & 6.57 & 0.93 & 0.850 & \\
\hline High repair tertile & 10 & $13 \cdot 70$ & 1.00 & $13 \cdot 29$ & $1 \cdot 28$ & 0.719 & 0.626 \\
\hline
\end{tabular}

* Damage is presented as mean percentage tail DNA and repair as mean incision activity in arbitrary units.

$\dagger$ Paired $t$ tests were performed within tertiles based on endogenous damage and DNA repair at baseline.

$\ddagger$ Analysis of covariance was used to compare post-intervention values between tertiles with baseline value as a covariate.

study of the extent to which SNP in genes encoding antioxidant protection proteins contribute to such inter-individual variation, but our related study of polymorphisms in genes encoding the NER system found that while no single polymorphism was associated with the NER capacity, there were significant gene-gene interactions ${ }^{(26)}$. Although the number of individuals in the present intervention study was small, we carried out a pilot investigation of possible influences of functionally significant SNP on DNA damage and repair and on responses to antioxidant nutrient supplementation. The data suggest that the Val allele of the MnSOD gene is more common in the group of volunteers with lower levels of endogenous DNA strand breaks, suggesting that there may be an association between this polymorphism and ability to defend DNA from oxidative stress. This is important in view of the recent observations that manganese superoxide dismutase is a major component of antioxidant protection in mitochondria ${ }^{(39)}$, and that the Val genotype confers increased antioxidant activity in vivo ${ }^{(28)}$. Furthermore, risk of prostate cancer was greater, and dependent on antioxidant status, in men homozygous for the Ala version of manganese superoxide dismutases ${ }^{(40)}$, which emphasises the potential importance of combined effects of SNP and nutritional status ${ }^{(41)}$. We hypothesise that the Val genotype confers greater protection from oxidative DNA damage.

Previous studies have produced inconsistent responses in levels of DNA damage to either increased intakes of fruits and vegetables or antioxidant supplementation. For example, antioxidant supplementation has been reported to decrease endogenous DNA damage in some studies $^{(9,42)}$ but not in others $^{(19)}$. Notably, in one study there were no effects in healthy volunteers ${ }^{(19)}$, but effects were apparent in smokers ${ }^{(9)}$ suggesting that lifestyle factors that affect endogenous DNA damage (or DNA repair) may influence the response to supplementation. The present study found that antioxidant supplementation had no effect on the level of DNA strand breaks when the cohort was analysed as a whole but, when stratified according to initial and pre-supplementation DNA damage, supplementation was accompanied by a significant fall in endogenous DNA damage. This suggests that individuals with higher levels of DNA strand breaks may benefit from antioxidant supplementation and is compatible with recent studies suggesting that the benefits of dietary supplementation may be apparent only in populations with low antioxidant status or with existing high levels of oxidative damage, for example in smokers ${ }^{(9)}$. The lack of effect of antioxidant supplementation in some studies ${ }^{(11,16,18,19,43)}$ may be a consequence of (adequate) dietary antioxidant status at baseline. Alternatively in individuals with a higher baseline antioxidant status, longer periods of supplementation may be required to influence DNA damage so that supplementation for 6 weeks as used in the present study may have been inadequate to elicit a lowering of DNA damage. Interestingly, a fall in endogenous oxidative damage was observed in both smokers and non-smokers after 20 weeks of supplemental antioxidants $^{(21)}$. Overall, such data indicate that inter-individual

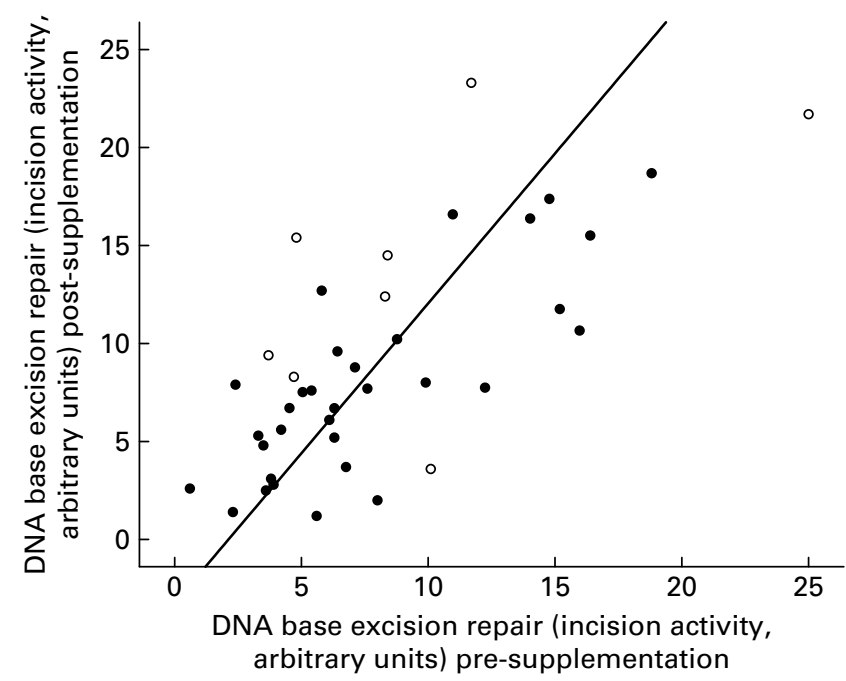

Fig. 3. Correlation between lymphocyte DNA repair capacity before and after supplementation. DNA repair capacity was measured at baseline and again 6 weeks later after antioxidant supplementation $(\bullet)$. For comparison, data from the control group measured on two occasions 6 weeks apart $(O)$ are also shown. 
Table 5. Relationship of DNA damage before and after supplementation with genotype for genes encoding proteins providing protection from oxidative stress*

(Mean values with their standard errors)

\begin{tabular}{|c|c|c|c|c|c|c|c|c|c|c|c|c|c|}
\hline \multirow[b]{3}{*}{ Polymorphism } & \multirow[b]{3}{*}{ Genotype } & \multicolumn{6}{|c|}{ Endogenous DNA damage (\% tail DNA) } & \multicolumn{6}{|c|}{ Peroxide-induced DNA damage (\% tail DNA) } \\
\hline & & \multicolumn{3}{|c|}{ Pre-supplement } & \multicolumn{3}{|c|}{ Post-supplement } & \multicolumn{3}{|c|}{ Pre-supplement } & \multicolumn{3}{|c|}{ Post-supplement } \\
\hline & & Mean & $n$ & SEM & Mean & $n$ & SEM & Mean & $n$ & SEM & Mean & $n$ & SEM \\
\hline \multirow{3}{*}{ MnSOD rs488T47C; Val16Ala } & $\mathrm{Val} / \mathrm{Val}$ & $16.46 \dagger$ & 11 & $6 \cdot 84$ & $19 \cdot 03$ & 11 & $8 \cdot 21$ & $17 \cdot 47$ & 11 & 8.59 & $17 \cdot 00$ & 11 & 8.14 \\
\hline & Val/Ala & 27.39 & 17 & 11.85 & $21 \cdot 72$ & 17 & $10 \cdot 40$ & $17 \cdot 04$ & 17 & $7 \cdot 18$ & $17 \cdot 26$ & 17 & $10 \cdot 74$ \\
\hline & Ala/Ala & 28.43 & 11 & $15 \cdot 37$ & $21 \cdot 24$ & 11 & 11.69 & $16 \cdot 81$ & 10 & 7.94 & 14.90 & 10 & 8.22 \\
\hline \multirow[t]{3}{*}{ GPX1 rs1050450; Leu198Pro } & Leu/Leu & $24 \cdot 20$ & 21 & 12.97 & 20.69 & 21 & $10 \cdot 95$ & 18.57 & 21 & 8.01 & $17 \cdot 66$ & 21 & $10 \cdot 28$ \\
\hline & Leu/Pro & $25 \cdot 10$ & 17 & $13 \cdot 05$ & $20 \cdot 68$ & 17 & $9 \cdot 27$ & $15 \cdot 06$ & 16 & 6.99 & $15 \cdot 69$ & 16 & 7.85 \\
\hline & Pro/Pro & $24 \cdot 64$ & 1 & & 28.51 & 1 & & $19 \cdot 26$ & 1 & & 7.65 & 1 & \\
\hline \multirow[t]{3}{*}{ GPX4 rs713041; T718C } & TT & 25.95 & 5 & 12.91 & $26 \cdot 05$ & 5 & $10 \cdot 52$ & $22 \cdot 22$ & 5 & 4.88 & $18 \cdot 26$ & 5 & $10 \cdot 70$ \\
\hline & TC & 24.50 & 23 & $13 \cdot 62$ & $18 \cdot 75$ & 23 & 8.05 & $15 \cdot 98$ & 22 & 8.46 & $15 \cdot 57$ & 22 & 9.41 \\
\hline & $\mathrm{CC}$ & $24 \cdot 21$ & 11 & 11.58 & $18 \cdot 75$ & 23 & 8.05 & $21 \cdot 16$ & 11 & $12 \cdot 90$ & $23 \cdot 72$ & 11 & 11.85 \\
\hline
\end{tabular}

GPX, glutathione peroxidase; MnSOD, manganese superoxide dismutase.

${ }^{*}$ Both endogenous and hydrogen peroxide-induced DNA damage is presented as mean percentage tail DNA and repair as mean incision activity in arbitrary units. Damage in groups of different genotype was compared using ANOVA.

† Significant differences between MnSOD genotypes $(P=0.03)$.

variation in parameters of DNA damage and repair should be taken into account in the design and analysis of antioxidant nutrient supplementation studies and that the subjects with higher baseline levels of DNA damage should be the focus of future studies ${ }^{(44)}$.

In contrast with the changes observed in DNA damage, the present study did not detect any effect of supplementation on BER measured using the modified comet assay. This is compatible with the lack of effect of fruit and vegetable supplementation on expression of DNA repair genes in young, healthy volunteers ${ }^{(15)}$ but is in contrast with the observed enhanced BER after supplementation with kiwi fruit $^{(23)}$. One explanation for the difference in findings between studies is that the volunteers in the kiwi fruit study were older (26-54 years) and likely to have higher adiposity and may therefore have had both greater DNA damage and a lower baseline repair capacity ${ }^{(25)}$. Note that, in the present study, we observed significant positive relationships between DNA damage and age (Fig. 1(a)) and BMI (Fig. 1(b)).

There was no observable association between endogenous DNA damage and BER, but measurement of NER in the same individuals showed an inverse association between NER and DNA damage ${ }^{(26)}$. This difference may reflect a relatively greater contribution of NER (compared with BER) to determination of baseline DNA damage or technical differences in the measurements of the two repair processes.

In conclusion, this intervention study has demonstrated that there is considerable inter-individual variation in the level of DNA damage, BER rates and the response in BER to an antioxidant supplement even among healthy, young non-smoking adults. Further investigation using multiple repeat measurements in each individual would help to define the relative contributions of intra-individual variation over time and inherent differences between individuals. Both endogenous DNA damage and the level of DNA damage induced by an oxidative challenge were reduced by supplementation in individuals with higher DNA damage levels before supplementation. Thus, the ability to respond to an oxidant challenge improved after antioxidant supplementation in individuals with initially lower ability to respond to such a challenge. Our hypothesis is that individuals who show high levels of DNA damage are limited in their antioxidant capacity and that damage may be reduced by dietary antioxidants i.e. individuals with higher levels of DNA damage are more likely to benefit from increased dietary antioxidant intake. Preliminary data suggest that a common polymorphism in the $M n S O D$ gene may have a role in determining levels of DNA damage. Future studies should take inter-individual variation and genetic factors into account, and there is a strong rationale for the proposition that the subjects with higher baseline levels of oxidative damage should be the focus of future studies ${ }^{(44)}$.

\section{Acknowledgements}

We thank Biotechnology and Biological Sciences Research Council for financial support (13/D15721), Wendy Bal for technical assistance and the volunteers for their participation in the DART study. The project was conceived by A. K. D., J. C. M., J. E. H. and E. A. W. The bulk of the work associated with the supplementation trial, genotyping and measurements of DNA damage and repair was carried out by F. C. and A. S., with help from B. B. and J. T. Data analysis was carried out by E. A. W., F. C., J. T. and A. K. D., and the manuscript was written by J. E. H., E. A. W., J. C. M. and F. C. There are no conflicts of interest for any of the authors.

\section{References}

1. Valko M, Leibfritz D, Moncol J, et al. (2007) Free radicals and antioxidants in normal physiological functions and human disease. Int J Biochem Cell Biol 39, 44-84.

2. Cooke MS, Evans MD, Dizdaroglu M, et al. (2003) Oxidative DNA damage: mechanisms, mutation, and disease. FASEB $J$ 17, $1195-1214$.

3. Dalle-Donne I, Rossi R, Colombo R, et al. (2006) Biomarkers of oxidative damage in human disease. Clin Chem 52, 601-623.

4. Klaunig JE \& Kamendulis LM (2004) The role of oxidative stress in carcinogenesis. Annu Rev Pharmacol Toxicol 44, 239-267.

5. Bernstein C, Bernstein H, Payne CM, et al. (2002) DNA repair/ pro-apoptotic dual-role proteins in five major DNA repair 
pathways: fail-safe protection against carcinogenesis. Mutat Res 511, 145-178.

6. Yu Z, Chen J, Ford BN, et al. (1999) Human DNA repair systems: an overview. Environ Mol Mutagen 33, 3-20.

7. WCRF/AICR (2007) Food, Nutrition, Physical Activity and the Prevention of Cancer: A Global Perspective. Washington, DC: AICR.

8. Pool-Zobel B, Bub A, Muller H, et al. (1997) Consumption of vegetables reduces genetic damage in humans: first results of a human intervention trial with carotenoid-rich foods. Carcinogenesis 18, 1847-1850.

9. Moller P, Loft S, Alfthan G, et al. (2004) Oxidative DNA damage in circulating mononuclear blood cells after ingestion of blackcurrant juice or anthocyanin-rich drink. Mutat Res 551, 119-126.

10. Zhao X, Aldini G, Johnson EJ, et al. (2006) Modification of lymphocyte DNA damage by carotenoid supplementation in postmenopausal women. Am J Clin Nutr 83, 163-169.

11. Bub A, Watzl B, Blockhaus M, et al. (2003) Fruit juice consumption modulates antioxidative status, immune status and DNA damage. $J$ Nutr Biochem 14, 90-98.

12. Riso S, Visioli F, Erba D, et al. (2004) Lycopene and vitamin C concentrations increase in plasma and lymphocytes after tomato intake. Effects on cellular antioxidant protection. Eur J Clin Nutr 58, 1350-1358.

13. Kang M, Park Y, Kim H, et al. (2004) Green vegetable drink consumption protects peripheral lymphocytes DNA damage in Korean smokers. Biofactors 22, 245-247.

14. Porrini M \& Riso P (2000) Lymphocyte lycopene concentration and DNA protection from oxidative damage is increased in women after a short period of tomato consumption. J Nutr 130, 189-192.

15. Moller P, Vogel U, Pedersen A, et al. (2003) No effect of 600 grams fruit and vegetables per day on oxidative DNA damage and repair in healthy nonsmokers. Cancer Epidemiol Biomarkers Prev 12, 1016-1022.

16. Astley S, Elliot R, Archer DB, et al. (2004) Evidence that dietary supplementation with carotenoids and carotenoid-rich foods modulates the DNA damage: repair balance in human lymphocytes. Br J Nutr 91, 63-72.

17. Briviba K, Kulling SE, Moseneder J, et al. (2004) Effects of supplementing a low-carotenoid diet with a tomato extract for 2 weeks on endogenous levels of DNA single strand breaks and immune functions in healthy non-smokers and smokers. Carcinogenesis 25, 2373-2378.

18. Wilms L, Hollman P, Boots A, et al. (2005) Protection by quercetin and quercetin-rich fruit juice against induction of oxidative DNA damage and formation of BPDE-DNA adducts in human lymphocytes. Mutat Res 582, 155-162.

19. Herbert K, Fletcher S, Chauhan D, et al. (2006) Dietary supplementation with different vitamin $\mathrm{C}$ doses: no effect on oxidative DNA damage in healthy people. Eur J Nutr 45, 97-104.

20. Park YK, Park E, Kim J-S, et al. (2003) Daily grape juice consumption reduces oxidative DNA damage and plasma free radical levels in healthy Koreans. Mutat Res 529, 77-86.

21. Duthie SJ, Ma A, Ross MA, et al. (1996) Antioxidant supplementation decreases oxidative DNA damage in human lymphocytes. Cancer Res 56, 1291-1295.

22. Moller P \& Loft S (2006) Dietary antioxidants and beneficial effect on oxidatively damaged DNA. Free Rad Biol Med 41, $388-415$

23. Collins AR, Harrington V, Drew J, et al. (2003) Nutritional modulation of DNA repair in a human intervention study. Carcinogenesis 24, 511-515.

24. Tyson J \& Mathers JC (2007) Dietary and genetic modulation of DNA repair in healthy human adults. Proc Nutr Soc 66, 42-51.

25. Mathers J, Coxhead J \& Tyson J (2007) Nutrition and DNA repair - potential molecular mechanisms of action. Curr Cancer Drug Targets 7, 425-431.
26. Tyson J, Caple F, Spiers A, et al. (2009) Inter-individual variation in nucleotide excision repair in young adults: effects of age, adiposity, micronutrient supplementation and genotype. Br J Nutr 101, 1316-1323.

27. Collins AR, Dunsinska M, Horvathova E, et al. (2001) Inter-individual differences in repair of DNA base oxidation, measured in vitro with the comet assay. Mutagenesis 16, 297-301.

28. Bastaki M, Huen K, Manzanillo P, et al. (2006) Genotypeactivity relationship for $\mathrm{Mn}$-superoxide dismutase, glutathione peroxidae 1 and catalase in humans. Pharmacogenet Genomics 16, 279-286.

29. Goode EL, Ulrich CM \& Potter JD (2002) Polymorphisms in DNA repair genes and associations with cancer risk. Cancer Epidemiol Biomarkers Prev 11, 1513-1530.

30. Zhang Y, Newcomb PA, Egan KM, et al. (2006) Genetic polymorphisms in base-excision repair pathway genes and risk of breast cancer. Cancer Epidemiol Biomarkers Prev 15, 353-358.

31. Vodicka P, Stetina R, Polakova V, et al. (2007) Association of DNA repair polymorphisms with DNA repair functional outcomes in healthy human subjects. Carcinogenesis 28, 657-664

32. Bingham S, Gill C, Welch A, et al. (1997) Validation of dietary assessment methods in the UK arm of EPIC using weighed records, and 24-hour urinary nitrogen and potassium and serum vitamin $\mathrm{C}$ and carotenoids as biomarkers. Int J Epidemiol 26, S137-S151.

33. Welch AA, Luben R, Khaw KT, et al. (2005) The CAFE computer program for nutritional analysis of the EPIC-Norfolk food frequency questionnaire and identification of extreme nutrient values. J Hum Nutr Diet 18, 99-116.

34. Nagah A \& Seal C (2005) In vitro procedure to predict apparent antioxidant release from wholgrain foods measured using three different analytical methods. J Sci Food Agric 85, 1177-1185.

35. Benzie IFF \& Strain JJ (1996) The ferric reducing ability of plasma (FRAP) as a measure of 'antioxidant power': the FRAP assay. Anal Biochem 239, 70-76.

36. Daly A, Steen V, Fairbrother K, et al. (1996) CYP2D6 multiallelism. Methods Enzymol 272, 199-210.

37. Paz-Elizur T, Elinger D, Leitner-Dagan Y, et al. (2007) Development of an enzymatic DNA repair assay for molecular epidemiology studies: distribution of OGG activity in healthy individuals. DNA Repair 6, 45-60.

38. Hamann I, Schwerdtle T \& Hartwig A (2009) Establishment of a non-radioactive cleavage assay to assess the DNA repair capacity towards oxidatively damaged DNA in subcellular and cellular systems and the impact of copper. Mutat Res $\mathbf{6 6 9}$, $122-130$

39. Sutton A, Imbert A, Igoudjil A, et al. (2005) The manganese superoxide dismutase Ala16Val dimorphism modulates both mitochondrial import and mRNA stability. Pharmacogenet Genomics 15, 311-319.

40. Li H, Kantoff PW, Giovannucci E, et al. (2005) Manganese superoxide dismutase polymorphism, prediagnostic antioxidant status, and risk of clinical significant prostate cancer. Cancer Res 65, 2498-2504.

41. Mathers JC \& Hesketh JE (2007) The biological revolution: understanding the impact of SNPs on diet-cancer interrelationships. J Nutr 137, 253S-258S.

42. Duthie SJ, Ma A, Ross MA, et al. (1996) Antioxidant supplementation decreases oxidative damage in human lymphocytes. Cancer Res 56, 1291-1295.

43. Duthie S, Jenkinson AM, Crozier A, et al. (2006) The effects of cranberry juice consumption on antioxidant status and biomarkers relating to heart disease and cancer in healthy human volunteers. Eur J Nutr 45, 113-122.

44. Freese R (2006) Markers of oxidative DNA damage in human interventions with fruit and berries. Nutr Cancer 54, $143-147$. 